\title{
Depression facilitators from the perspective of Iranian patients with major depressive disorder: a qualitative research
}

\author{
Milad Rezaiye ${ }^{1}$ (D) Moloud Radfar ${ }^{2^{*}}$ (D) and Masumeh Hemmati MaslakPak ${ }^{3}$
}

\begin{abstract}
Background: Major depressive disorder is the most common psychological disorder and affects many people worldwide. Therefore, it is important to identify the factors that cause or facilitate this disorder.

Objectives: The aim of this qualitative study was to identify the facilitating factors of depression from the perspective of Iranian patients with major depressive disorder.

Methods: This qualitative study was conducted by content analysis method. Data were collected via purposeful sampling (maximum variation sampling) by conducting semi-structured interviews until reaching data saturation. Indepth interviews were conducted with 12 participants, including patients with major depressive disorder and their families in Razi Psychiatric Training and Treatment Center in Urmia (RPsTT) from November 2018 to February 2020. The process of data analysis was based on the Landman and Grenheim method. The accuracy and trustworthiness of the data were obtained through the Lincoln and Guba criteria.

Results: The analysis of interviews with the participants indicated four major categories: a. Environmental factors (approved by 8 participants), b. Attitudinal factors (approved by 12 participants), c. Economic factors (approved by 9 participants) and d. Situational factors (approved by 10 participants).

Conclusion: In order to prevent major depressive disorder or to reduce the signs of this disorder and improve these patients quality of life, paying attention to the facilitating factors from patient's perspective based on their community culture can be effective. Among facilitating factors, attitudinal factors have the most impact on the incidence and exacerbation of this disorder from the perspective of patients.
\end{abstract}

Keywords: Depression, Facilitation, Major depressive disorder, Perspective, Qualitative research

\section{Introduction}

Major depressive disorder $\left(\mathrm{MDD}^{1}\right)$ is a complex mood disorder characterized by persistent and overwhelming depression [1]. It is a debilitating psychiatric disorder characterized by pervasive depressed mood, anhedonia, cognitive disability, and suicidal tendency $[1,2]$. In the

${ }^{1}$ Major depressive disorder

* Correspondence: radfar.m@umsu.ac.ir

${ }^{2}$ Faculty of Nursing and Midwifery, Urmia University of Medical Sciences, Urmia, Iran

Full list of author information is available at the end of the article most recent surveys, major depressive disorder has the highest lifetime prevalence (almost 17\%) of any psychiatric disorders [3].

Approximately 350 million people worldwide have major depressive disorder $[4,5]$. In other words, depression has been diagnosed in nearly $4 \%$ of the world's population with a prevalence of $16.6 \%$ throughout life, which has a major impact on social and public health [6]. Suicide rate in these patients is $4 \%$ and its recurrence rate is high and increases social and economic burdens [1]. A study by Sharifi et al., on the prevalence of psychiatric disorders in Iran, showed that the most
Springer Open (c) The Author(s). 2021 Open Access This article is licensed under a Creative Commons Attribution 4.0 International License, which permits use, sharing, adaptation, distribution and reproduction in any medium or format, as long as you give appropriate credit to the original author(s) and the source, provide a link to the Creative Commons licence, and indicate if changes were made. The images or other third party material in this article are included in the article's Creative Commons licence, unless indicated otherwise in a credit line to the material. If material is not included in the article's Creative Commons licence and your intended use is not permitted by statutory regulation or exceeds the permitted use, you will need to obtain permission directly from the copyright holder. To view a copy of this licence, visit http://creativecommons.org/licenses/by/4.0/. 
common psychiatric disorder in Iran was major depressive disorder with a prevalence of $12.7 \%[7,8]$.

Major depressive disorder is a serious health threat and will be the second leading cause of diseases by 2030 [9]. The serious developmental consequences of depression and the associated treatment challenges once it has developed underscore the need for programs aimed at prevention [10]. Given the recurrent nature of the disorder, it is important not just to treat the acute episode, but also to protect against its return and the onset of subsequent episodes. Several types of interventions have been shown to be efficacious in treating depression. The antidepressant medications are relatively safe and work for many patients, but there is no evidence that they reduce risk of recurrence once their use is terminated [11].

Numerous factors have been cited in various studies as facilitators of depression. For example, in a study by Person et al., environmental stressors such as mass disasters were cited as a contributing factor to depression [12]. Deadly diseases such as cancers have been mentioned as other causes of depression [13]. In addition to these factors, disability can also be a predisposing factor for depression [14]. In general, the results of such studies have reported some factors as predictors of depression. These factors include couple communications [15], self-esteem [16], experience of body image issues [17], and genetics factors [18].

However, most authors who examined risk factors for onset of MDD did not discriminate a first onset of MDD from recurrent MDD [19]. In addition, often studies did not have sufficient power to examine the differential impact of risk factors on a first onset of MDD in men and women. Insight into these risk factors may assist physicians and policy makers in determining who is more susceptible to depressive symptoms to prevent the onset of MDD and its associated burden of disease [9].

Therefore, it is necessary to first evaluate patients' perceptions of the depression facilitation factors to assess the quality of life of their community [20]. To identify depression facilitators in patients with major depressive disorder and with regard to the characteristics of qualitative studies, which makes it possible to describe phenomena, understand the relationships between phenomena and processes. The present study is a qualitative research utilizing a qualitative content analysis approach to discover new perspectives, new concepts and to communicate between them [21]. Qualitative research is a form of social research, where people interpret their experiences and the world in which they live. Qualitative methods are used to reveal people's behavior, views, feelings, and experiences to understand the social realities of individuals, groups, and cultures [22].

The objective of this study was to carry out an exploration to understand the Iranian patients with major depressive disorder perceptions about causes and risk factors for this disorder. Therefore, with regard to the mentioned characteristics of qualitative studies, the use of qualitative research method with qualitative content analysis approach is appropriate for the purpose of this study.

\section{Methods \\ Design of study}

This study is part of a master's thesis. That lasted from November 2018 to February 2020. This study is a conventional content analysis. Conventional content analysis is generally used with a study design whose aim is to describe a phenomenon, in this case the emotional reactions of hospice patients. This type of design is usually appropriate when existing theory or research literature on a phenomenon is limited [23].

Semi-structured interviews were conducted with patients who were undergoing current treatment for major depressive disorder in Razi Psychiatric Training and Treatment Center in Urmia (RPsTT ${ }^{2}$ ).

The research environment consists of 3 in-patient wards of RPsTT. This hospital is the psychiatric center of Urmia City and patients with all kinds of mental disorders are referred to this hospital from all centers.

\section{Participant}

Ethical committee approval was obtained. Then, purposive sampling was started among patients with major depressive disorder and continued until data saturation. This is the method of conscious selection of specific participants by the researcher. All attempts are made to enter participants with the specified status [24]. Purposive sampling strategies are designed to enhance understandings of selected individuals or groups' experience(s) or for developing theories and concepts. Researchers seek to accomplish this goal by selecting "information rich" cases, that is individuals, groups, organizations, or behaviors that provide the greatest insight into the research question [25].

Participants in this study were selected as having been diagnosed with major depressive disorder by their treated psychiatrist and had been in hospital for at least 2 weeks. They were also able to speak and were willing to participate in the study.

Participant selection and interviews with participants continued until the data were replicated.

The study included 12 participants, 7 men and 3 women with major depressive disorder and 2 families of these patients with varying age, occupation, education, and marital status. During the interviews with the patients and the analysis of the data, the researchers were

\footnotetext{
${ }^{2}$ Razi Psychiatric Training and Treatment Center in Urmia
} 
directed to the interviews with their family caregivers. In this study, there were two family caregivers (without depression) who were in close relationship with these patients and were able to fully describe the living conditions of these patients to the research team and confirm or deny the patients' statements.

Participants of this study had been referred to a psychiatric clinic and policlinic for neurological or suicidal problems and had been admitted to the RPsTT after being diagnosed with major depressive disorder.

\section{Inclusion and exclusion criteria}

Inclusion criteria included depressed patients admitted to RPsTT with a psychiatrist's diagnosis based on DSM5 criteria, fluent in Farsi or Turkish and interested in participating in the study, the patients participating in this study were individuals who had experienced several episodes of major depression and at least 2 weeks had passed since their last hospitalization at the time of the interview, and they were under drug treatment and psychologically stable to be interviewed (a stable mood that they were able to communicate with the researcher and share their experiences). (Patient health records were used to extract the necessary information.)

Exclusion criteria were self-report of the presence of other physical or mental illness or lack of interest in continuing to participate in the study.

\section{Interviews}

These patients were invited by the head nurses and the researcher to participate in this study. The study area was different parts of RPsTT; a quiet, non-commuter room was chosen as the place for the interview.

Written or verbal informed consent was obtained from all participants. After explaining the purpose and necessity of the study, the researcher reminded the participants of their commitment to adhere to all ethical principles such as confidentiality, anonymity, and permission to discontinue or leave the study and access to what they have stated.

The length of the interview varied from 35 to $60 \mathrm{~min}$ depending on the participant's willingness. Participants were interviewed in 2 or 3 sessions depending on the conditions of the interview to obtain rich and complete data. The researcher also conducted subsequent interviews to ensure that he had a common understanding of the data with participant (for member checking). Generally, a total of 35 interview sessions with participants were conducted during the study. All interviews were conducted when MDD patients had passed through the acute episode of the disorder and had a stabilized mood and were able to talk and share their experiences.
There was an interview guide for the semi-structured interviews which included questions such as the following:

1. What factors affect you?

2. What causes depression in you?

3. And...

In order to maintain confidentiality and anonymity, participants were given aliases in this study. Also, one of the characteristics of the interviewer (first author) in this study is that before the study, the researcher had completed his internship in this psychiatric medical center, but at the time of the research, he did not have any therapeutic or care relationship with the patients of that medical center.

\section{Analysis}

To analyze the data in this study, the content of the interviews was recorded during individual interviews with participants, then transcribed verbatim and then typed into the software (MAXQDA10).

After the interviews were completed, all the interviews were coded according to the conventional content analysis method and the concepts were extracted. The process of data analysis was based on the Landman and Grenheim method in 2004 [26]. The following steps were taken in this study:

1. The interviews were conducted and then reviewed several times to find the correct understanding of the whole case.

2. Semantic units were extracted from the interviews and then categorized as compact units.

3. Based on the concept of meaning in semantic units, these units were carried out to the level of abstraction and were labeled with codes.

4. The codes were compared in terms of similarities and differences and were categorized under more abstract categories with distinct labels.

5. By comparing the classes with each other and delving deeply into them, the content of the data is presented as the theme.

A sample of the trend of condensation-abstraction process in this study is shown in Table 1.

\section{Trustworthiness of research}

Lincoln and Guba's trustworthiness criteria and techniques were used to ensure the validity and reliability of the qualitative data $[27,28]$.

To ensure credibility, review and peer review has been used by participants and partners. During the interview, the audience was given feedback and endorsed speech 
Table $1 \mathrm{~A}$ sample of the trend of condensation-abstraction process in this study

\begin{tabular}{llll}
\hline $\begin{array}{l}\text { Main } \\
\text { category/ } \\
\text { theme }\end{array}$ & Subcategories & Open code & Meaning units \\
\hline $\begin{array}{lll}\text { Attitudinal } \\
\text { factors }\end{array}$ & $\begin{array}{l}\text { 1. Negative } \\
\text { attitudes around } \\
\text { people } \\
\text { 2. Negative self- } \\
\text { concept }\end{array}$ & $\begin{array}{l}\text { Exacerbation of depression with } \\
\text { negative attitudes of others due to lack }\end{array}$ & $\begin{array}{l}\text { You also know that if someone doesn't have a job, how do they look at } \\
\text { him? When they look in that case to me, it makes me depressed.. (P7) (Male. } \\
\text { Patient). }\end{array}$ \\
& feeling of imperfection & $\begin{array}{l}\text { After my sister got married and I couldn't get married, I felt that maybe I had } \\
\text { a flaw that made no one want to marry me, and I gradually became more } \\
\text { depressed.. (P8) (Female. Patient). }\end{array}$ \\
\hline
\end{tabular}

by him/her. In the review by colleagues, the coding and classification process was reviewed by other members of the group, and in cases where there was disagreement; discussions were held until agreement was reached. Also, other methods have been used, like prolonged engagement, devoting enough time, and good relationship with participant.

For transferability, rich descriptions were written detailing their environment, participants, and non-verbal behaviors; also, demographic characteristics of the participants were reported and varied sampling was performed to increase transferability.

The confirm ability was verified through external reviewers; the coding and classification process was approved by two experts in the field of qualitative research.

In order to assess the dependability, the study process, was described in detail and research notes were carefully written.

One of the problems in this study was patients' lack of confidence and their poor co-operation in the research. Interviews were held in several sessions with each individual to resolve this problem.

\section{Results}

Demographic characteristics showed that the youngest participant was 19 and the oldest was 48 years old; the lowest level of education was illiterate and the highest was bachelor's degree (Table 2).

After content analysis, there were factors that led to depressive disorder or aggravated depression signs. Therefore, these factors were categorized as facilitating factors of depression in 4 categories and 8 subcategories (Table 3).

\section{First category: environmental factors}

Environmental factors are one of the most influential factors in depression. In this study, environmental factors include external factors that severely affect the depressed person. This factor includes two subcategories: 1.Intensifying depression symptoms with sunset and 2 . exacerbation of depressive symptoms with seasonal changes.

\section{Intensifying depression symptoms with sunset}

Eight participants reported that sunset caused or aggravated the symptoms of depression. So that by sunset and at night, these patients will have symptoms of low mood. Patients reported that most of their depression symptoms were seen at night and they saw the sunset as a major cause of the depression.

P9 (male. patient): On the other hand, when the weather cools down and it gets dark early, my heart

Table 2 Demographic characteristics of the participants

\begin{tabular}{|c|c|c|c|c|c|}
\hline Rows & Alias & Age & Education & Job & Marital status \\
\hline 1 & Patient/male & 37 & Diploma & Welder & Married \\
\hline 2 & Patient/male & 23 & Under diploma & Hand selling & Single \\
\hline 3 & Patient/male & 48 & Diploma & Military retiree & Married \\
\hline 4 & Patient/male & 41 & Bachelor & Military officer & Married \\
\hline 5 & Patient/male & 29 & Illiterate & Driver & Married \\
\hline 6 & Patient/male & 32 & Elementary & Unemployed & Single \\
\hline 7 & Patient/male & 47 & Under diploma & Lawn mower & Married \\
\hline 8 & Patient/female & 34 & Under diploma & Housewife & Married \\
\hline 9 & Patient/female & 44 & Illiterate & Housewife & Married \\
\hline 10 & Patient/female & 19 & Diploma & Unemployed & Single \\
\hline 11 & Patient's wife & 26 & Under diploma & Housewife & Married \\
\hline 12 & Patient's mom & 44 & Diploma & Housewife & Married \\
\hline
\end{tabular}


Table 3 The categories and subcategories of the data

\begin{tabular}{ll}
\hline Categories & Subcategories \\
\hline $\begin{array}{ll}\text { 1. Environmental } & \text { a. Intensifying depression symptoms with sunset } \\
\text { b. Intensifying depression symptoms with seasonal } \\
\text { variations }\end{array}$ \\
$\begin{array}{ll}\text { 2. Attitudinal factors } & \text { a. Negative attitudes of around people } \\
& \text { b. Negative self-concept } \\
\text { 3. Economic factors } & \text { a. The impact of financial problems on depression } \\
\text { 4. Situational } & \text { b. Unemployment causes depression } \\
\text { factors } & \text { a. Depression incidence followed by loss }\end{array}$
\end{tabular}

aches and I feel suffocated.

P5 (male. patient): I like it to be always sunny because when it gets dark at night I get nervous and I always think about it.

P6 (male. patient): I wish it was always morning Just go to the garden in the nature I hate the night, I always feel bad, I wish it was always the day, I think the night gets me more depressing.

\section{Exacerbation of depressive symptoms with seasonal changes}

Six participants said that as the cold season arrives, especially with the onset of autumn, they feel depressed, and climate changes lead to the exacerbation of their depression. Patients said that as the cold season approached, they would lose their relaxation and efficiency, and on the other hand, there would be symptoms of depression and body weakness.

P6 (male. patient): When the fall comes I become more depressed. Most of the time I get sick in the fall, I feel like I can't work.

\section{Second category: attitudinal factors}

Depressed patients are strongly influenced by attitudinal factors. Participants stated that other's negative attitudes toward them lead to an increase in depression symptoms. These patients emphasized the need for family member's attention to the individual's position in society and the family and stated that they needed a proper position in their family. On the other hand, negative selfesteem and feeling defective or unable to work in certain areas of life lead to exacerbation of depression in these patients. Therefore, attitude factors are composed of two sub-categories, which include the following:

1. Negative attitudes of around people

2. Negative self-concept.

\section{Negative attitudes of around people}

According to this study, we found that depressed patients are very impressionable. They can be easily influenced. Study participants were strongly affected by other's attitudes, and especially their negative attitudes about him/her status in society led to depression in that patient. Ten patients declared that one of the things that causes others to have a negative attitude toward them and that affects them a lot is the lack of proper position in society and lack of jobs.

P7 (male. patient): You know that if anyone doesn't have any job, how they look at him in society and when I have that attitude I get more depressed. And also I didn't have good position in our family. They looked bad to me. That was very impressive in my depressive disorder.

\section{Negative self-concept}

Self-concept includes our attitudes, feelings, and knowledge about social ability, skill, and receptivity. Selfconcept encompasses all aspects of cognitive, perceptual, emotional, and evaluation procedures. An image everyone has in mind. Therefore, one's set of attitudes to himself is called self-concept [29]. All of the participants had a negative concept of them and had a lack of selfesteem, leading to a sense of depression in them. Patients participating in the study did not foresee a suitable position for themselves in society, and they always felt deficient, inadequate ability, and defective in themselves.

P7 (male. patient): After we sold the store we bought a house but my family did not like it. And it destroyed my morale. I always say to myself I could not glorify my family. We were running away from parties and gatherings because they didn't value us, so we would have preferred to stay home even when we were invited to a place where we wouldn't see the value. In my family, when you don't have money, you don't have good position you don't have any value. When I think about these things and feel that problem is from me it makes me more depressed.

P8 (female. patient): After my sister got married and I stayed home, I was jealous of her and said why I can't get married. Perhaps I have problem and it made me depressed.

\section{Third category: economic factors}

Other factors from the patient's point of view that have a significant impact on the degree of satisfaction of depressed patients and can lead to the prevalence of depression in society are economic factors. According to 
this study in the area of economic factors, factors such as financial problems, lack of money, loss of belongings due to unemployment, lack of a fixed job, and loss of employment lead to an increase in the prevalence of depression in individuals. This category included of two subcategories: 1.The impact of financial problems on depression and 2. Unemployment causes depression.

\section{The impact of financial problems on depression}

Economic instability and financial problems are among the factors that can easily lead to depression and affect patient's entire lives. Nine participants mentioned that lack of money, loss of money, and financial problems have exacerbated their depression, or their depressive symptoms increase with the lack of money and lack of income.

P5 (male. patient): Financial problems have had a huge impact on my illness. All patients like me have a huge financial problem with their illness.

P9 (female. patient): My husband had gone bankrupt. We sold the house, we sold the car. All of them made me depressed.

P4 (male. patient): I have financial problem, and this problem is pushing me to the point that I always think of money that I have to give back and that makes me depressed.

\section{Unemployment causes depression}

Five participants found unemployment to be a cause of their depression. For example, not having a permanent job or being fired and losing a job has led to depression. Most of these patients said they are very upset about not having a permanent job. Others said they were so eager to find a job that they became depressed after they could not find a job, and some of them said that they are depressed after being fired.

P5 (male. patient): The biggest disadvantage of not having a permanent job is I waste all of the money that I get from one day work and then when I cannot find another work to do and get money it makes me depressed.

P7 (male. patient): Overall, I was depressed for the two years I was out of work. Unemployment bothered me a lot and made me depressed.

\section{Fourth category: situational factors}

Situational factors are influences that do not occur from within the individual but from elsewhere like the environment and others around you. From the perspective of participants in this study, patients are deeply affected and depressed by the loss of loved ones as their parents. Other situational factors are the retirement crisis that patients indicated they were dissatisfied with their retirement and tended to continue working because retirement had negative effects in their life, like feeling of lack of energy. Thus, the category of situational factors consists of two subcategories, including: 1.Depression incidence followed by loss and 2.Retirement crisis.

\section{Depression incidence followed by loss}

It is not easy to endure the death of loved ones and overcome the sadness that comes with it, but over time, it can be a relief. Unfortunately, sometimes the recovery process is delayed and your social performance will be severely disrupted. Ten participants indicated that they were depressed with the loss of their parents or other loved ones and that lack caused them depressed.

P8 (female. patient): My mom was very kind to me. I was depressed when she died. She liked me so much she talked to me well, she said me to pray, to pay attention to my personal hygiene.

\section{Retirement crisis}

From the perspective of patients, retirement can be a synonym for a nightmare. Many retirees, therefore, view retirement as not only an opportunity to pursue their favorite activities, but also view retirement as a serious threat and a nightmare. One of our contributors believed that he would feel sick after he retired. He had no interest in retirement and was interested to continue in the service, even protesting his retirement and committing suicide for failing to return to work. Another participant considered retirement as a loss of social value.

P3 (male. patient): I was depressed since I retired, I was good at my job, I wanted to work there, I didn't want to retire, even complained about retirement, but after my retirement my morale was so bad.

\section{Discussion}

In this study, factors called depression facilitators had a significant effect on the onset and exacerbation of depressive symptoms. Patients with major depression, and their families mentioned in interviews that environmental factors, attitudinal factors, economic factors, and situational factors are among the factors affecting the lives of these patients and can greatly increase their depressive symptoms. The mentioned factors with the aggravation of depressive symptoms have a great effect on destroying the interest of these people to continue living and continuously deprive them of a sense of satisfaction and enjoyment of life. On the other hand, by eliminating or reducing the mentioned factors, it is possible to help improve the quality of life of these patients and reduce the severity of MDD's symptoms. 
The first factor to alleviate depression is paying attention to the environmental factors. Patients believe that with sunset and the onset of autumn, depressive symptoms may develop or worsen. In this regard, Patten et al. reported that the burden of major depressive illness was much higher in the winter months than in the summer months [30]. In another study, Rottenberg et al. reported that sunsets were a major cause of mood swings and depression [31]. A study by Gartlehner et al. found that the risk of recurrence of major depression increases with the onset of autumn and winter [32].

The second factor in the occurrence or intensification symptoms of depression is attitude factors. Patients believe that other people's attitudes toward them have a high impact on their depression, and some of these patients also have a type of negative self-concept. Regarding attitudinal factors, a study has been conducted by Zhang et al. It indicates that negative attitudinal factors in the community, especially the stigma label of mental illness, lead to aggravation of mental disorders. According to Zhang, patients with mental disorders are less acceptable to others in the community. In addition, the families of these patients consider the existence of such a member as a disgrace, which is referred to as family stigma [33]. Risch et al. also believe that low self-esteem or negative self-esteem in depressed patients leads to recurrence of major depressive episodes [34]. Kuehner et al. also point out in their study that in order to improve the quality of life of patients with major depression, their self-esteem and social support should be enhanced [35].

The third effective factor for these patients is economic factors. These patients believe that they become depressed by unemployment and lack of jobs, as well as by the financial problems. In this regard, Simon reports in his study that factors such as financial problems and job loss have a great impact on causing depression, and also depression causes a deterioration of the functional and occupational status of the person and has high costs for the depressed person and his/her family [36]. Gürhan also points out that most depressed patients have an unfavorable economic situation, and this low economic situation leads to worsening of the disorder and even suicide in these people [37].

And finally, situational factors are other causes of depression in these patients. According to the results of the data, the loss and loss of loved ones have led to symptoms of depression in them. Friedman et al. also write that the experience of grief following the loss of a loved one is an understandable and acceptable reaction. However, in some people, it can have deeper effects and cause various symptoms of major depression. As a result of losing loved ones, people suffering from major depression experience a major crisis, become pessimistic, and lose their self-esteem [38]. Djelantik et al. also note that depressed patients who lose loved ones experience a more intense period of grief [39].

In the present study, our participants considered retirement as an important cause of depression. However, a study by Lee and Smith found that retirement does not lead to depression, and it leads to reduced labor force participation. However, in the continuation of their study, they point out that retirees are often more depressed than workers [40]. While in the opinion of the participants in our society, job is a kind of recreation and social activity, and on the other hand, income decreases with retirement and creates economic problems for the retiree, and therefore retirement can lead to depression or its aggravation. Karpansalo et al. also reported in their study that depression leads to early retirement [41]. Butterworth et al. also have indicated that people who have retired have experienced various mental health crises compared to the time they were employed [42].

Proper knowledge of facilitator factors for depression helps to increase the detective power [43]. Therefore, in addition to proper screening of prevalent cases, early detection of people who are likely to develop a depressive disorder in the near future is desirable [44]. Also perspectives may vary among patients according to their cultural values, beliefs, and practices, and by race/ethnicity, rural/urban status, or sexual orientation, among other factors [45]. So, we can control the major depressive disorder in a community by being aware of the cultural conditions that influence depression from the perspective of its population. For example, in the present study, attitudinal factors were more important from the perspective of this group of people than other factors, and this result is different from other studies. From the point of view of these people, attitude factors have a significant impact on the incidence and exacerbation of depression. However, with a special focus on creating a positive attitude towards these people, their mood increases and their recovery accelerates.

\section{Conclusion}

Based on our results, factors that facilitate depression in Iran include environmental factors, attitude factors, economic factors, and situational factors. And from the perspective of patients with depressive disorder and their families in Iranian society, there is a strong relationship between exacerbation of depression and these factors. This study adds to our understanding of depression facilitators in Iranian society and affective factors cause depression or severe this disorder. The current results could help the care givers to understand the perspective of Iranian patients with major depressive disorder about the facilitating factors of depression and provide suitable, 
effective, practicable, and culture-based mental health services and also help to reduce the symptoms of depression in these patients. Therefore, it is suggested that further qualitative and interventional studies should be conducted in this area.

\section{Relevance for clinical practice}

Health professionals and care givers have to pay more attention to the facilitation factors of depression from the perspective of patients with major depressive disorder, because knowing these factors can significantly control the symptoms of major depressive disorder in patients.

\section{Limitations}

Of the existing problems in this study can be attributed to the patients' lack of trust and their poor cooperation in the research. In order to solve this problem, several interviews were conducted with each person to conduct an interview in this field after obtaining the patient's trust.

Due to the nature of qualitative studies, the results of this study are cautiously generalized.

\section{Abbreviations \\ MDD: Major depressive disorder; RPsTT: Razi Psychiatric Training and Treatment Center in Urmia}

\section{Acknowledgements}

This article is taken from the dissertation of the master's degree course in approved and defended psychiatry at the Faculty of Nursing, Urmia University of Medical Sciences. The authors consider it necessary to express our sincere gratitude to the staff of Razi Psychiatric Training and Treatment Center in Urmia (RPsTT), research officials of Urmia School of Nursing and the jury of the dissertation who helped us to perform and improve the quality of this research. The authors would like to thank all participants of the study for their willingness despite their emotional burdens.

\section{Authorship statement}

All authors listed meet the authorship criteria according to the latest guidelines of the International Committee of Medical Journal Editors, and all authors are in agreement with the manuscript.

\section{Authors' contributions}

MRa conceived of the idea and research questions and assisted with analyses, aided in the interpretation of the results, and assisted in writing the results section. MRe helped to conceive the research questions, conducted interviews with the participants, conducted the analyses, and prepared the first complete draft of the manuscript. MHM helped to conceive the research questions, assisted with analyses, aided in the interpretation of the results, and contributed to the writing of the manuscript. All authors have read and approved the manuscript

\section{Funding}

The study is funded by Urmia University of Medical Sciences; however, the funder was not involved in the design of the study and collection, analyses, and interpretation of data and in writing the manuscript.

\section{Availability of data and materials}

All our study-related information is stored in secure folders with limited access. Electronic data files are stored on a file system with access restricted to designated researchers and data managers. The dataset is available from the corresponding author at Urmia University of Medical Sciences.

\section{Declarations}

\section{Ethics approval and consent to participate}

This research was approved by the Urmia University of Medical Sciences Research Ethics Committee (IR.UMSU.REC.1398.214). And after received a letter of introduction through the research directorate at the Urmia University of Medical Sciences along with other necessary permits issued by the dean's office and the offices of the nursing staff, the researcher entered the location of the research to familiarize the participants with the aim and process of the research and to obtain their informed verbal and written consent to participation in the research by giving interviews and being observed. Measures were put in place to ensure that the identity of each participant remained confidential. The researcher provided the participants with contact information and was ready at all times to answer their queries about the research.

\section{Consent for publication}

Not applicable.

\section{Competing interests}

The authors declare that they have no competing interests.

\section{Author details}

'Department of Psychiatric Nursing, School of Nursing and Midwifery, Urmia University of Medical Sciences, Urmia, Iran. ${ }^{2}$ Faculty of Nursing and Midwifery, Urmia University of Medical Sciences, Urmia, Iran. ${ }^{3}$ Maternal and Childhood Obesity Research Center, Urmia University of Medical Sciences, Urmia, Iran.

Received: 18 May 2020 Accepted: 22 March 2021

Published online: 31 March 2021

\section{References}

1. Zhi D, Calhoun VD, LV L, Ma X, Ke Q, Fu Z, et al. Aberrant dynamic functional network connectivity and graph properties in major depressive disorder. Frontiers in psychiatry. 2018;9:339. https://doi.org/10.3389/fpsyt.201 8.00339 .

2. Trivedi MH. Major depressive disorder: remission of associated symptoms. J Clin Psychiatry. 2006;67(suppl 6):27-32.

3. Vandeleur CL, Fassassi S, Castelao E, Glaus J, Strippoli M-PF, Lasserre AM, et al. Prevalence and correlates of DSM-5 major depressive and related disorders in the community. Psychiatry research. 2017;250:50-8. https://doi. org/10.1016/j.psychres.2017.01.060.

4. $\quad$ Sugg HVR, Richards DA, Frost J. Morita Therapy for depression (Morita Trial): a pilot randomised controlled trial. BMJ open. 2018;8(8):e021605. https://doi. org/10.1136/bmjopen-2018-021605.

5. López E, Steiner AJ, Manier K, Shapiro BB, Vanle B, Parisi T, et al. Quality of life and functioning of Hispanic patients with Major Depressive Disorder before and after treatment. J Affective Disorders. 2018;225:117-22. https:// doi.org/10.1016/j.jad.2017.08.031.

6. Ouakinin SR, Barreira DP, Gois CJ. Depression and obesity: Integrating the role of stress, neuroendocrine dysfunction and inflammatory pathways. Front Endocrinology. 2018;9:431. https://doi.org/10.3389/fendo.2018.00431.

7. Sharifi V, Amin-Esmaeili M, Hajebi A, Motevalian A, Radgoodarzi R, Hefazi M, et al. Twelve-month prevalence and correlates of psychiatric disorders in Iran: the Iranian Mental Health Survey, 2011. Archives of Iranian medicine. 2015;18(2):0-.

8. Amini K, Marks D, Cheraghi MA, Eftekhar M, Negarandeh R. Attempting to Restore Integrity of the Self: A Grounded Theory Study of Recovery From Major Depressive Disorder. Journal of the American Psychiatric Nurses Association. 2019;25(5):385-95. https://doi.org/10.1177/1078390318800585.

9. Stegenga BT, King M, Grobbee DE, Torres-González F, Švab I, Maaroos H-I, et al. Differential impact of risk factors for women and men on the risk of major depressive disorder. Annals of epidemiology. 2012;22(6):388-96. https://doi.org/10.1016/j.annepidem.2012.04.011.

10. Garber J, Clarke GN, Weersing VR, Beardslee WR, Brent DA, Gladstone TR, et al. Prevention of depression in at-risk adolescents: a randomized controlled trial. Jama. 2009;301(21):2215-24. https://doi.org/10.1001/jama.2 009.788 . 
11. Hollon SD, Thase ME, Markowitz JC. Treatment and prevention of depression. Psychological Science in the public interest. 2002;3(2):39-77. https://doi.org/10.1111/1529-1006.00008.

12. Person C, Tracy M, Galea S. Risk factors for depression after a disaster. The Journal of nervous and mental disease. 2006;194(9):659-66. https://doi.org/1 0.1097/01.nmd.0000235758.24586.b7.

13. Tang B, Liu X, Liu Y, Xue C, Zhang L. A meta-analysis of risk factors for depression in adults and children after natural disasters. BMC public health. 2014;14(1):1-12.

14. Anstey KJ, von Sanden C, Sargent-Cox K, Luszcz MA. Prevalence and risk factors for depression in a longitudinal, population-based study including individuals in the community and residential care. Am J Geriatr Psychiatry 2007;15(6):497-505. https://doi.org/10.1097/JGP.0b013e31802e21d8.

15. Cluxton-Keller F, Priest JB, Denton WH. Couple communication patterns as predictors of major depressive disorder symptoms: an exploratory study. The American Journal of Family Therapy. 2015;43(5):395-412. https://doi. org/10.1080/01926187.2015.1070700.

16. Canlı D, Karaşar B. Predictors of major depressive disorder: the need for social approval and self-esteem. Anatolian Journal of Psychiatry/Anadolu Psikiyatri Dergisi. 2021;22(1)

17. Farrer LM, Gulliver A, Bennett K, Fassnacht DB, Griffiths KM. Demographic and psychosocial predictors of major depression and generalised anxiety disorder in Australian university students. BMC Psychiatry. 2016;16(1):1-9.

18. Shadrina M, Bondarenko EA, Slominsky PA. Genetics factors in major depression disease. Frontiers in psychiatry. 2018;9:334. https://doi.org/10.33 89/fpsyt.2018.00334.

19. Kessler RC. Epidemiology of women and depression. J Affective Dis. 2003; 74(1):5-13. https://doi.org/10.1016/S0165-0327(02)00426-3.

20. Wettergren L, Lindberg MH, Kettis $\AA$, Glimelius B, Ring L. Comparison of two instruments for measurement of quality of life in clinical practice-a qualitative study. BMC Med Res Methodology. 2014;14(1):115. https://doi. org/10.1186/1471-2288-14-115.

21. McAlearney AS. Leadership development in healthcare: a qualitative study. J Organizational Behav. 2006;27(7):967-82. https://doi.org/10.1002/job.417.

22. Fossey E, Harvey C, McDermott F, Davidson L. Understanding and evaluating qualitative research. Australian \& New Zealand J Psychiatry. 2002; 36(6):717-32. https://doi.org/10.1046/j.1440-1614.2002.01100.x

23. Hsieh H-F, Shannon SE. Three approaches to qualitative content analysis. Qualitative health research. 2005;15(9):1277-88. https://doi.org/10.1177/104 9732305276687

24. Tongco MDC. Purposive sampling as a tool for informant selection. Ethnobotany Research Applications. 2007;5:147-58. https://doi.org/10.17348/ era.5.0.147-158.

25. Devers K, Frankel R. Study design in qualitative research - 2: Sampling and data collection strategies. Education Health. 2000;13(2):263-71. https://doi. org/10.1080/13576280050074543.

26. Graneheim UH, Lundman B. Qualitative content analysis in nursing research: concepts, procedures and measures to achieve trustworthiness. Nurse Education Today. 2004;24(2):105-12. https://doi.org/10.1016/j.nedt.2003.10. 001.

27. Lemon $L L$, Hayes J. Enhancing trustworthiness of qualitative findings: Using Leximancer for qualitative data analysis triangulation. Qualitative Rep. 2020; 25(3):604-14.

28. Nowell LS, Norris JM, White DE, Moules NJ. Thematic analysis: Striving to meet the trustworthiness criteria. Int J Qualitative Methods. 2017;16(1): 1609406917733847.

29. Möller J, Zitzmann S, Helm F, Machts N, Wolff F. A meta-analysis of relations between achievement and self-concept. Rev Educational Res. 2020;90(3): 376-419. https://doi.org/10.3102/0034654320919354.

30. Patten S, Williams J, Lavorato D, Bulloch A, Fiest K, Wang J, et al. Seasonal variation in major depressive episode prevalence in Canada. Epidemiology and psychiatric sciences. 2017;26(2):169-76. https://doi.org/10.1017/S2045796015001183.

31. Rottenberg J, Hindash AC. Emerging evidence for emotion context insensitivity in depression. Current Opinion in Psychology. 2015;4:1-5. https://doi.org/10.1016/j.copsyc.2014.12.025.

32. Gartlehner G, Nussbaumer-Streit B, Gaynes BN, Forneris CA, Morgan LC, Greenblatt $A$, et al. Second-generation antidepressants for preventing seasonal affective disorder in adults. Cochrane Database of Systematic Reviews. 2019:3.

33. Zhang Z, Sun K, Jatchavala C, Koh J, Chia Y, Bose J, et al. Overview of stigma against psychiatric illnesses and advancements of anti-stigma activities in six Asian societies. Int J Environmental Research Public Health. 2020;17(1):280.
34. Risch AK, Buba A, Birk U, Morina N, Steffens MC, Stangier U. Implicit selfesteem in recurrently depressed patients. J Behav Ther Experimental Psychiatr. 2010;41(3):199-206. https://doi.org/10.1016/j.jbtep.2010.01.003.

35. Kuehner $\mathrm{C}$, Buerger $\mathrm{C}$. Determinants of subjective quality of life in depressed patients: the role of self-esteem, response styles, and social support. J Affective Dis. 2005;86(2-3):205-13. https://doi.org/10.1016/j.jad.2 005.01.014.

36. Simon GE. Social and economic burden of mood disorders. Biological Psychiatry. 2003;54(3):208-15. https://doi.org/10.1016/S0006-3223(03)004207.

37. Gürhan N, Beşer NG, Polat Ü, Koç M. Suicide risk and depression in individuals with chronic illness. Community Mental Health J. 2019;55(5):8408. https://doi.org/10.1007/s10597-019-00388-7.

38. Friedman RA. Grief, depression, and the DSM-5. New Engl J Med. 2012; 366(20):1855-7. https://doi.org/10.1056/NEJMp1201794.

39. Djelantik AMJ, Robinaugh DJ, Kleber RJ, Smid GE, Boelen PA. Symptomatology following loss and trauma: Latent class and network analyses of prolonged grief disorder, posttraumatic stress disorder, and depression in a treatment-seeking trauma-exposed sample. Depression Anxiety. 2020;37(1):26-34. https://doi.org/10.1002/da.22880.

40. Lee J, Smith J. Work, Retirement, and Depression. J Population Ageing. 2009:2(1-2):57-71. https://doi.org/10.1007/s12062-010-9018-0.

41. Karpansalo M, Kauhanen J, Lakka T, Manninen P, Kaplan G, Salonen J. Depression and early retirement: prospective population based study in middle aged men. Journal of Epidemiology \& Community Health. 2005; 59(1):70-4. https://doi.org/10.1136/jech.2003.010702.

42. Butterworth P, Olesen S, Villamil E, Melzer D, Rodgers B, Anstey K. Retirement and mental health: Analysis of the Australiannational survey of mental health and well-being; 2006

43. Beekman AT, de Beurs E, van Balkom AJ, Deeg DJ, van Dyck R, van Tilburg W. Anxiety and depression in later life: co-occurrence and communality of risk factors. Am J Psychiatry. 2000;157(1):89-95. https://doi.org/10.1176/ajp.1 57.1.89.

44. Beekman A, Deeg D, Geerlings S, Schoevers R, Smit J, Van Tilburg W. Emergence and persistence of late life depression: a 3-year follow-up of the Longitudinal Aging Study Amsterdam. J Affective Dis. 2001;65(2):131-8. https://doi.org/10.1016/S0165-0327(00)00243-3.

45. Colligan EM, Cross-Barnet C, Lloyd JT, McNeely J. Barriers and facilitators to depression screening in older adults: a qualitative study. Aging \& Mental Health. 2020;24(2):341-8. https://doi.org/10.1080/13607863.2018.1531376.

\section{Publisher's Note}

Springer Nature remains neutral with regard to jurisdictional claims in published maps and institutional affiliations.

\section{Submit your manuscript to a SpringerOpen ${ }^{\circ}$ journal and benefit from:}

- Convenient online submission

- Rigorous peer review

- Open access: articles freely available online

- High visibility within the field

- Retaining the copyright to your article

Submit your next manuscript at $>$ springeropen.com 